\title{
NICOLAS VEYSMAN, Mise en scène de l'opinion publique dans la littérature des Lumières
}

\section{Paola Salerni}

\section{(2) OpenEdition}

\section{Journals}

\section{Edizione digitale}

URL: http://journals.openedition.org/studifrancesi/33233

DOI: 10.4000/studifrancesi.33233

ISSN: 2427-5856

\section{Editore}

Rosenberg \& Sellier

\section{Edizione cartacea}

Data di pubblicazione: 1 décembre 2005

Paginazione: 643-644

ISSN: 0039-2944

\section{Notizia bibliografica digitale}

Paola Salerni, «Nicolas veysman, Mise en scène de l'opinion publique dans la littérature des Lumières», Studi Francesi [Online], 147 (XLX | III) | 2005, online dal 01 novembre 2015, consultato il 18 avril 2021. URL: http://journals.openedition.org/studifrancesi/33233 ; DOI: https://doi.org/10.4000/studifrancesi. 33233

Questo documento è stato generato automaticamente il 18 avril 2021.

\section{(c) (i) (9)}

Studi Francesi è distribuita con Licenza Creative Commons Attribuzione - Non commerciale - Non opere derivate 4.0 Internazionale. 


\title{
NICOLAS VEYSMAN, Mise en scène de l'opinion publique dans la littérature des Lumières
}

\author{
Paola Salerni
}

\section{NOTIZIA}

NICOLAS VEYSMAN, Mise en scène de l'opinion publique dans la littérature des Lumières, Paris, Champion, 2004 («Les Dix-huitièmes siècles», 85), pp. 801.

1 Nel ricco volume Nicolas Veysman attraverso la storia delle idee evidenzia i cambiamenti del concetto di «opinione pubblica» nei sistemi di pensiero settecenteschi. L'indagine, sorretta da un aggiornato apparato critico, vaglia il senso dell'aggettivo public nel sintagma composto, distinguendo le valenze semantiche del referente unitario da quelle dell'epiteto postposto.

2 Fondamentale appare l'opposizione tra l'identificazione dell'opinione con l'oscuro e inerte errore instillato dal clero nello spirito del popolo, «communauté ignorante et tumultueuse» (p. 48), «malade, exclu de l'âge de raison» (p. 93), corpo collettivo «inapte au jugement critique» (p. 126) lontano dalla scena politica, ma - come ricorda Arlette Farge - resistente alla censura monarchica, e l'esigenza di una chiara e razionale verità pubblica nata dal libero pensiero e dalla circolazione delle idee.

3 Nel Settecento la rappresentazione filosofica la vuole autonoma nell'accedere alla verità sulla fermentazione dialettica di tutti i convincimenti diffusi tra il pubblico. Per Alain Rey è questa nozione a segnalarsi nel 1765 con Rousseau nel Contrat social, ma, secondo Veysman, si tratta più di una filosofia utopica che di una realtà sociale.

4 Nel denso capitolo "Les ambivalences du public d'art" l'analisi si sposta in alcuni luoghi emblematici, la vita parigina sempre più distinta dal resto della Francia, la società dello spettacolo, il suo parterre, e affronta la ricezione drammaturgica e l'interpretazione pittorica, la posizione censoria di Louis Sébastien Mercier e Diderot nei confronti del 
pubblico francese, la cui opinione «est réduite à la clandestinité et au secret» (p. 143). L'esigenza fondamentale è il discernere l'opinione «vraie», della pluralità e dell'oralità teatrali, dalla testualità filosofica: avvolti nella stessa emozione dello spettacolo, public e peuple sono accomunati nel corpo retorico della «métaphore électrique» (p. 162) e separati dalla successiva figura dell'hydre, immagine funzionale a rappresentare il popolo come voce insidiosa, mostro pregno di tratti peggiorativi tramandati al secolo posteriore con un'accezione maggiormente politicizzata.

5 Nel 1733 il Traité de l'opinion di Le Gendre ne fa il solo e principale oggetto di studio, ma il 1762 è il riferimento cronologico suggerito da Alain Rey nel Dictionnaire historique de la langue française come primo riscontro indiziario. Tuttavia, malgrado le figé e l'oscillazione lessicale tra «rumeur populaire» e «connaissance incertaine et douteuse», la nozione risulta inserita nel processo di "civilisation", superando l'assimilazione religiosa e filosofica all'errore grazie alla nuova definizione voltairiana di "histoire des opinions" (1758). Pur considerato il principale innovatore dell'«histoire des moeurs» non è Voltaire a operare l'importante conversione: sulla traccia di Fontenelle, l'opinione come oggetto di una storia universale è per lui un margine statico, un'ombra proiettata dal progresso storico dell'umanità. Neppure Montesquieu, inventore di una dinamica concezione politica di stampo nazionale, si rende protagonista dell'avanzamento concettuale, essendo difensore di un'idea mai menzionata nella sua opera. Entrambi, però, preparano una riabilitazione che Duclos nel 1751 fa sua: il moralista, come sostiene anche Michel Delon, «donne la mesure», osserva e individua nelle «consciences» e nei costumi del secolo il momento specifico della storia di una civiltà preda di tensioni contrastanti.

6 La consacrazione di "opinione pubblica" come detentrice ed enunciatrice della verità è resa possibile dal lavoro dei filosofi che la inseriscono nella logica del progresso prima morale con Duclos e l'abbé Petiot, poi scientifico con D'Alembert. Dal 1771 per i parlamentari Servan e Malesherbes è attiva forza politica, in grado di svolgere un ruolo coesivo per la società civile, "peuple», "public» e «nation» capaci di misurarsi con l'autorità sovrana. Invero, secondo la più recente critica storica esaminata da Veysman, la realtà dell'epoca è radicalmente differente dall'immagine proposta dai Philosophes; e anche il carattere borghese è stato ugualmente messo in dubbio. È piuttosto fra la nobiltà "éclairée", disposta a capire la filosofia illuminista che il concetto di opinione pubblica trova credibilità o diffondendosi in spazi privati e clandestini, come ritiene Jürgen Habermas.

7 La storia della lettura è il secondo momento della strategia persuasiva e mistificatrice degli Illuministi: l'autore individua il pubblico reale dei Philosophes in margine al quale, secondo l'apporto di Jean-Marie Goulemot, delimita l'esistenza e l'influenza di un pubblico immaginario. Nuovo è, dunque, il legame fra l'ideologia e il sociale: per Pierre Bourdieu già il concettualizzare l'idea di opinione equivale a costituire e legittimare i rapporti di forza che la fondano e la rendono possibile. L'effetto fondamentale della congiunzione dei due aspetti è una risposta attiva al discorso filosofico, meccanismo combinatorio del «génie national». Decisivo è in questa direzione l'apporto di Michel Foucault, che articola lo studio delle pratiche discorsive con quello delle azioni affermandone la rispettiva esteriorità e specificità.

8 Veysman rivendica la coesistenza frammentaria di molteplici realtà che travalicano una concezione totalitaria, sia essa linguistica, sociale o storica. Fatta eccezione per Condorcet, si può dire che intorno al 1780 la generazione dei Philosophes sparisca. La 
comunità degli autori e la loro identità cambiano; la ricezione non cessa con la Rivoluzione né dopo essa, ma mutano il senso e la funzione da attribuire al concetto. Non è, quindi, corretto sostenere che i prodromi della Rivoluzione si scorgono fra gli illuministi: l'idea di opinione è correlativa alla loro azione riformatrice e a quella contestataria dei parlamentari.

9 Benché il saggio si chiuda con gli anni 1787-1788, questa data segna l'evoluzione dell'opinione-utopia nel sintagma sinonimo «voix publique» e nelle nozioni di «esprit public» e «conscience publique». Il popolo assurge a protagonista del progresso anche linguistico, si inserisce nell'immaginario filosofico, messo alla prova dagli oratori della Rivoluzione e ancor più dall'azione dei giornalisti: la funzione del letterato diventa quella di proteggere il popolo contro quanti vogliono abusare della sua ignoranza. L'idea di opinione pubblica costruisce questa nuova frontiera che la Rivoluzione abbatte costituendo una rinnovata cultura politica. La Rivoluzione eredita tutta la varietà semantica della definizione, rovesciata nel tragitto da soggetto passivo a ideale attivo incarnato in ogni “citoyen”, al quale si può infine riconoscere un'opinion publique. 